\title{
When a ribosomal protein grows up - the ribosome assembly path of Rps3
}

\author{
Brigitte Pertschy* \\ Institute of Molecular Biosciences, University of Graz, Graz, Austria. \\ * Corresponding Author: \\ Brigitte Pertschy, E-mail: brigitte.pertschy@uni-graz.at
}

The biogenesis of ribosomes is a central process in all dividing cells. Eukaryotic ribosomes are composed of a large $60 \mathrm{~S}$ and a small $40 \mathrm{~S}$ subunit, each comprising a complex assembly of ribosomal RNA (rRNA) and ribosomal proteins ( $r$-proteins). The synthesis of these constituents is spatially separated, with r-proteins being produced by translation in the cytoplasm, while rRNA is generated by transcription in the nucleus. Hence, the arrangement of r-proteins and rRNA into large ribonucleoprotein complexes requires dedicated mechanisms ensuring their encounter in the same compartment. To this end, r-proteins need to be safely delivered to the nucleus where they assemble with the rRNA. Beyond these initial challenges, the synthesis of ribosomes does not merely comprise the joining of $r$-proteins with rRNA, but occurs in a complex assembly line involving multiple maturation steps, including the processing and folding of rRNA. R-proteins usually have composite rRNA binding sites, with several different rRNA helices contributing to the full interaction. Not all of these interaction sites may already be accessible at the point when an r-protein is incorporated, necessitating that some of the r-protein-rRNA contacts are formed at later maturation stages. In our two recent studies, we investigated the ribosome assembly path of r-proteins in the yeast Saccharomyces cerevisiae using the small subunit r-protein S3 (Rps3) as a model. Our studies revealed intricate mechanisms to protect the protein, transport it into the nucleus, integrate it into pre-ribosomal precursor particles and promote its final stable association with $40 \mathrm{~S}$ subunits.
To familiarize you with these mechanisms, I invite you to join in with me in following the early life of Rps3 from its birth, through its cumbersome journey to the nucleus, its constricted initial allocation in pre-40S particles, until its conquest of a stable position in the $40 \mathrm{~S}$ subunit (also shown in the model in Figure 1).

Like most r-proteins, free Rps3 (outside its "natural" context in the ribosome) is prone to aggregation, presumably due to its high content in positive charges, which causes non-specific interactions with RNA [1]. To prevent such undesired interactions, Rps3's delicate regions are shielded by two mechanisms. Firstly, already while it is being synthesized, Rps3's N-terminus is bound by a specific, "dedicated" chaperone, the ankyrin repeat protein Yar1 (Figure 1, Step I) [1,2]. Secondly, Rps3's C-terminus dimerizes with a second Rps3 molecule by domain swapping of two beta-strands (Figure 1, Step II) $[3,4]$.

Surprisingly, we found that in vivo only one of the Rps3s within the dimer is bound by Yar1 [3]. A potential explanation for this unexpected architecture comes from the observation that the Yar1 binding site is positioned directly adjacent to the nuclear localization signal (NLS) of Rps3 [5]. NLSs comprise the binding sites for importins, which mediate the transport of proteins through the nuclear pores into the nucleus [6]. Our analyses suggest that several redundant routes engage in Rps3 import, with major contribution from the classical importin $\alpha /$ importin $\beta$ pathway [5]. We found that binding of importin $\alpha$ (Kap60 in yeast) competed with Yar1 for binding to Rps3, suggesting that one $\mathrm{N}$-domain of Rps3 can only bind either importin or Yar1 (Figure 1, Step III). As we nevertheless detected complexes containing Rps3 and both Yar1 and Kap60 in vivo, Rps3-dimers with Yar1 bound to one and importin bound

COMMENT on: Mitterer V, Gantenbein N, Birner-Gruenberger R, Murat G, Bergler H, Kressler D and Pertschy B (2016). Nuclear import of dimerized ribosomal protein Rps3 in complex with its chaperone Yar1. Sci Rep. 6:36714. doi: 10.1038/srep36714.

AND

Mitterer V, Murat G, Réty S, Blaud M, Delbos L., Stanborough T, Bergler H, Leulliot N, Kressler D and Pertschy B (2016). Sequential domain assembly of ribosomal protein S3 drives 40S subunit maturation. Nat Commun. 7:10336. doi: 10.1038/ncomms10336. 
to the second Rps3 $\mathrm{N}$-domain might represent the preferred conformation for nuclear import [5]. It is still a puzzle how such architecture is retained, but assuming that the complex is imported immediately after one of the two Yar1 copies has been replaced by importin, the limited time for a second importin to access the second Rps3 copy might make it simply more likely that one Yar1 is maintained. After nuclear import and dissociation of importin (Figure 1, Step IV), Rps3 is incorporated into pre-40S particles, permitting that the two protective mechanisms for Rps3 transport are dismissed again by resolving Rps3 dimers and releasing Yar1 (Figure 1, Step V). Yar1 release is presumably promoted by binding of a new partner to the Rps3 N-domain, the ribosome assembly factor Ltv1 [3]; this may happen either before, upon, or shortly after Rps3 incorporation. It is not known how exactly Rps3 dimers are disassembled, but potentially, integration of one Rps3 sterically constraints the second Rps3, which might consequently be competed away. Although the exact positioning of Rps3 within these pre-40S particles is not known, Rps3 definitely cannot be assembled in its mature conformation, considering that Ltv1 not only associates with the Rps3 Ndomain, but also occupies the rRNA site, which is entitled to the Rps3 $\mathrm{N}$-domain in mature $40 \mathrm{~S}$ subunits $[3,7,8]$. We observed that the Rps3 $\mathrm{N}$-domain alone fused to GFP dis- plays a nuclear localization, suggesting it cannot be integrated into pre-40S particles and co-exported into the cytoplasm; consequently, the Rps3 C-domain may comprise the main anchorage of Rps3 within pre-40S particles [5].

Last but not least, after pre-40S export, Ltv1 has to be removed in order that Rps3 can move into its correct position [3]. At least two different events are critical for Ltv1 release, the order of which is not yet clear (Figure 1, Step $\mathrm{VI})$; (i) the formation of contacts between the Rps3 Ndomain and another ribosomal protein, Rps20, which might compete Ltv1 away from one of its rRNA binding sites [3] and (ii) phosphorylation of Ltv1 by the kinase Hrr25, which presumably causes electrostatic repulsion $[3,9,10]$. Together, these events cumulate in the release of Ltv1, allowing for the final, stable incorporation of Rps3 into 40 S subunits (Figure 1, Step VII).

Together, our two studies revealed an unexpected complexity of the ribosome assembly path of Rps3. Although the details will certainly vary between different $r$ proteins, similar mechanisms as utilized by Rps3 may also be employed by other r-proteins. The engagement of dedicated chaperones was also reported for some other $r$ proteins in recent years, and more dedicated r-protein chaperones might still await their discovery [2,11-21].

An intriguing observation in our study was the dimeri-

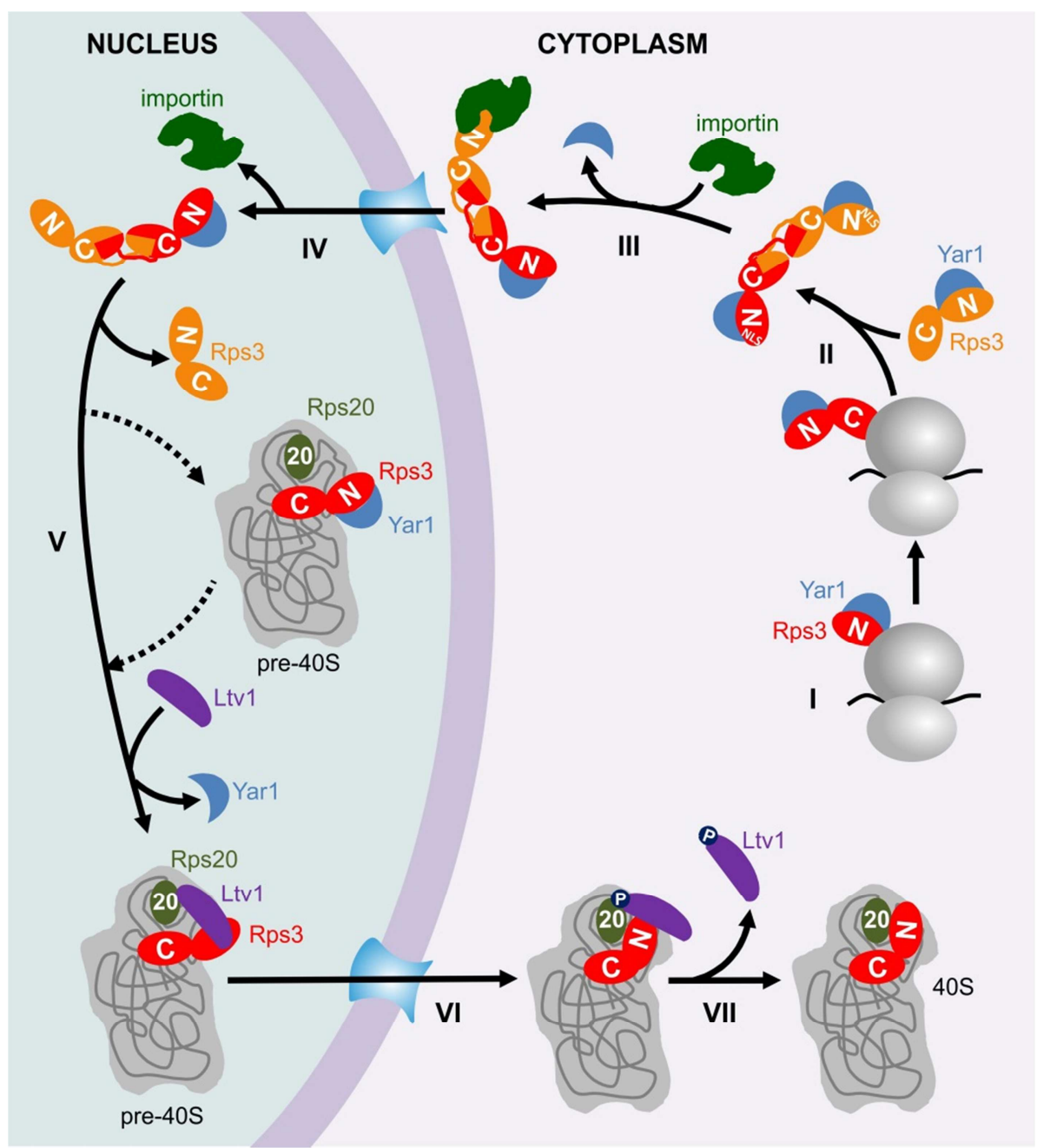

FIGURE 1: The ribosome assembly path of Rps3. I. The N-domain of Rps3 is cotranslationally bound by the chaperone Yar1. II. The C-domain of Rps3 dimerizes with a second Rps3 C-domain by domain swapping. III. One copy of Yar1 is removed by competition with importin, which binds to the $\mathrm{N}$-terminal NLS of one of the Rps3s. IV. The complex is transported into the nucleus, where the importin is released. v. One Rps3 copy is incorporated into pre-40S particles. Either after (dashed arrows) or already before Rps3 joins pre-40S, Yar1 is released and replaced by the assembly factor Ltv1. The presence of Ltv1 in pre-40S particles prevents Rps3 from attaining its final position. VI. Presumably after export of pre-40S particles into the cytoplasm, phosphorylation of Ltv1 and contacts between the Rps3 $\mathrm{N}$-domain and ribosomal protein S20 (Rps20) lead to the release of Ltv1 and the final stable incorporation of Rps3 (VII). 
zation of Rps3, which we suppose functions in protecting the C-terminal domain of Rps3 from non-specific interactions. Another r-protein, Asc1, was also reported to form dimers [22]. Hence, dimerization might be a universal strategy also used by other r-proteins to shield important sites from non-specific interactions.

Last but not least, we characterized a mechanism ensuring the controlled stepwise incorporation of an $r$ protein by means of selective occlusion of rRNA binding sites by an assembly factor. This might provide the necessary time to sculpture the respective region before it encounters its r-protein binding partner. Subsequently, the respective assembly factor must be released in order to allow the r-protein to form its contacts with the initially withholded sites. Considering that in the course of ribosome maturation, 250 non-ribosomal proteins bind preribosomal particles at different stages in the pathway, it is likely that, analogously to Ltv1, also other assembly factors impede the full incorporation of $r$-proteins and that assembly factor release is connected to the stable integration of the respective $r$-proteins.

The investigation of the particular mechanisms utilized in the assembly paths of other $r$-proteins will be an interesting subject for future studies.

\section{REFERENCES}

1. Koch B, Mitterer V, Niederhauser J, Stanborough T, Murat G, Rechberger G, Bergler H, Kressler D, and Pertschy B (2012). Yar1 protects the ribosomal protein Rps3 from aggregation. J Biol Chem 287(26): 21806-21815.

2. Pausch $P$, Singh $U$, Ahmed $Y L$, Pillet $B$, Murat $G$, Altegoer $F$, Stier $G$, Thoms M, Hurt E, Sinning I, Bange G, and Kressler D (2015). Cotranslational capturing of nascent ribosomal proteins by their dedicated chaperones. Nat Commun 6: 7494.

3. Mitterer V, Murat G, Réty S, Blaud M, Delbos L, Stanborough T, Bergler H, Leulliot N, Kressler D, and Pertschy B (2016). Sequential domain assembly of ribosomal protein S3 drives 40S subunit maturation. Nat Commun 7: 10336.

4. Holzer S, Ban N, and Klinge S (2013). Crystal Structure of the Yeast Ribosomal Protein rpS3 in Complex with Its Chaperone Yar1. J Mol Biol 425(22): 4154-4160.

5. Mitterer V, Gantenbein N, Birner-Gruenberger R, Murat G, Bergler $H$, Kressler D, and Pertschy B (2016). Nuclear import of dimerized ribosomal protein Rps3 in complex with its chaperone Yar1. Sci Rep 6: 36714.

6. Chook YM and Süel KE (2011). Nuclear import by karyopherin- $\beta$ s: recognition and inhibition. Biochim Biophys Acta 1813(9): 1593-1606.

7. Granneman S, Petfalski E, Swiatkowska A, and Tollervey D (2010). Cracking pre-40S ribosomal subunit structure by systematic analyses of RNA-protein cross-linking. EMBO J 29(12): 2026-2036.

8. Ben-Shem A, Garreau de Loubresse N, Melnikov S, Jenner L, Yusupova G, and Yusupov M (2011). The structure of the eukaryotic ribosome at $3.0 \AA$ A resolution. Science 334(6062): 1524-1529.

9. Schäfer T, Maco B, Petfalski E, Tollervey D, Böttcher B, Aebi U, and Hurt E (2006). Hrr25-dependent phosphorylation state regulates organization of the pre-40S subunit. Nature 441(7093): 651-655.

\section{ACKNOWLEDGMENTS}

This work was supported by grants P27996-B21 and P28874-B21 from the Austrian Science Fund (FWF) to Brigitte Pertschy.

\section{CONFLICT OF INTEREST}

The author states that she has no conflict of interests.

\section{COPYRIGHT}

(C) 2017 Pertschy. This is an open-access article released under the terms of the Creative Commons Attribution (CC BY) license, which allows the unrestricted use, distribution, and reproduction in any medium, provided the original author and source are acknowledged.

Please cite this article as: Brigitte Pertschy (2017). When a ribosomal protein grows up - the ribosome assembly path of Rps3. Microbial Cell 4(5): 140-143. doi: 10.15698/mic2017.05.571

10. Ghalei H, Schaub FX, Doherty JR, Noguchi Y, Roush WR, Cleveland $\mathrm{JL}$, Stroupe ME, and Karbstein K (2015). Hrr25/CK1ס-directed release of Ltv1 from pre-40S ribosomes is necessary for ribosome assembly and cell growth. J Cell Biol 208(6): 745-759.

11. Pillet B, Mitterer V, Kressler D, and Pertschy B (2017). Hold on to your friends: Dedicated chaperones of ribosomal proteins: Dedicated chaperones mediate the safe transfer of ribosomal proteins to their site of pre-ribosome incorporation. BioEssays News Rev Mol Cell Dev Biol 39(1): 1-12.

12. Schaper S, Fromont-Racine M, Linder $P$, de la Cruz J, Namane A, and Yaniv $M$ (2001). A yeast homolog of chromatin assembly factor 1 is involved in early ribosome assembly. Curr Biol CB 11(23): 18851890.

13. louk TL, Aitchison JD, Maguire S, and Wozniak RW (2001). Rrb1p, a yeast nuclear WD-repeat protein involved in the regulation of ribosome biosynthesis. Mol Cell Biol 21(4): 1260-1271.

14. West M, Hedges JB, Chen A, and Johnson AW (2005). Defining the order in which Nmd3p and Rpl10p load onto nascent 60S ribosomal subunits. Mol Cell Biol 25(9): 3802-3813.

15. Eisinger DP, Dick FA, Denke E, and Trumpower BL (1997). SQT1, which encodes an essential WD domain protein of Saccharomyces cerevisiae, suppresses dominant-negative mutations of the ribosomal protein gene QSR1. Mol Cell Biol 17(9): 5146-5155.

16. Ting Y-H, Lu T-J, Johnson AW, Shie J-T, Chen B-R, Kumar S. S, and Lo K-Y (2017). Bcp1 Is the Nuclear Chaperone of Rpl23 in Saccharomyces cerevisiae. J Biol Chem 292(2): 585-596.

17. Schütz $S$, Fischer $U$, Altvater $M$, Nerurkar $P$, Peña $C$, Gerber $M$, Chang Y, Caesar S, Schubert OT, Schlenstedt G, and Panse VG (2014). A RanGTP-independent mechanism allows ribosomal protein nuclear import for ribosome assembly. eLife 3: e03473. 
18. Peña C, Schütz S, Fischer U, Chang Y, and Panse VG (2016). Prefabrication of a ribosomal protein subcomplex essential for eukaryotic ribosome formation. elife 5 .

19. Pillet B, García-Gómez JJ, Pausch P, Falquet L, Bange G, de la Cruz J, and Kressler D (2015). The Dedicated Chaperone Acl4 Escorts Ribosomal Protein Rpl4 to Its Nuclear Pre-60S Assembly Site. PLOS Genet 11(10): e1005565.

20. Kressler D, Bange G, Ogawa Y, Stjepanovic G, Bradatsch B, Pratte D, Amlacher S, Strauß D, Yoneda Y, Katahira J, Sinning I, and Hurt E (2012). Synchronizing nuclear import of ribosomal proteins with ribosome assembly. Science 338(6107): 666-671.
21. Stelter P, Huber FM, Kunze R, Flemming D, Hoelz A, and Hurt E (2015). Coordinated Ribosomal L4 Protein Assembly into the PreRibosome Is Regulated by Its Eukaryote-Specific Extension. Mol Cell 58(5): 854-862.

22. Yatime L, Hein KL, Nilsson J, and Nissen P (2011). Structure of the RACK1 dimer from Saccharomyces cerevisiae. J Mol Biol 411(2): 486498. 